\title{
Global Markets, Leadership and Public Governance
}

\author{
Gianfranco Rebora*
}

\begin{abstract}
The entrepreneurship is a crucial factor, especially in a global competitiveness context. Thus, the companies are not likely to share their strategic, organizational and managerial models, quite the opposite, they commit to produce something unique and inimitable which constitute a winning model's framework.

Being unique and, consequently, kindle emotions and generate positive energy that involve personnel, clients, suppliers has surely a leadership connotation. Naturally, it is possible to find this kind of companies not only in the European context, but also in U.S and Asian emerging markets.

Thus, it is necessary for managers to consider cultural, industrial, social and markets diversity, abandoning any kind of uniformity or standardization claim. The managers have to reflect and listen, otherwise it is impossible to take advantage from diversity nor to increase the value of uniqueness.
\end{abstract}

Keywords: Public Governance; Leadership; Global Capitalism; Global Corporations; Global Markets

\section{Against the crisis: to normalize or to regulate?}

Probably we should blame the crisis looming over Italian economy and its managerial class for putting the firm in the center of the debate concerning the State's system future. Consequently, such situation has caused concern about the Italian industry competitiveness.

In fact, any other debate has caused so much concern as the actual one. In particular, two phenomenon have emerged: a remarkable awareness towards the firm's propelling role and the firm's relation with other components of the system involving political, institutional, cultural and social factors. As a result, we can certify a key-actor role of the firm, which strengths or weaknesses determine the State's competitiveness in global markets. A relation (institutionalized or not) emerged between the firm and society, on the other hand, configures a capitalist

\footnotetext{
Full Professor of Business Administration, LIUC - Libera Università Carlo Cattaneo (grebora@liuc.it)
} 
model, which in a global context may become a winning formula or a crushing defeat generator, a source of prosperity or a reason of decline.

The following assumption seems empirically confirmed by different positions, polarized primarily in two separate currents generating two antithetic action models: normalization and regulation.

The normalization process, according to some authors, can be easily referable to the Italian capitalism anomalies by comparison with the most relevant international benchmarks. In particular, it contemplates the phenomenon like uncompleted liberalization, poor dimensions of Italian companies respect to other ones operating in the global context, financial system's obsolescence, the State's favouritism, a low growth rate of Italian stock market, and at the end, the State's passive role in helping the companies to grow (Crapelli, 2004). The Italian case has been retained particularly interesting by numerous authors who emphasize the elitist character of the Italian system. Rajan and Zingales (2004), for instance, talk about the capitalism degeneracy in Italy, where "the system is made by elite and for elite". Although a free market concept is the most virtuous and beneficial form of economic institution, it stands on extremely fragile basis, all the more in countries like Italy, destitute of a stable market infrastructure and with a privileged but inefficient elite. As the Italian study case shows, the open market is practicable only if fallowed by antitrust practices, an appropriate tax structure as also by corporate governance regulations (Rajan-Zingales, 2004).

All the considerations regarding the economy liberalization spring from a rational and conscious economic analysis of global markets context. As result, a stress has been put on identifying the aspects that promote a free market concept and, consequently, a competitiveness.

On the contrary, numerous papers claiming the supremacy of firm's regulation concept, judged the normalization process application as a spectacular failure. Luciano Gallino, has clearly described the impact of "conceptual revolution" in the 80 's and 90's on the capitalism reorganization model, developed firstly in United States and in Great Britain and secondly in Germany, France and Italy. What's more, the normalization scheme fallows the shareholders value maximization as a primary objective and strives to ennoble new shareholders-centered managerial capitalism. The fallowing logic emphasizes the relevance of financial performance in the short-term as also relieves the Board of Directors of any responsibility that is unrelated to shareholders interest. Furthermore, numerous and devastating scandals as well as the crisis itself may be easily referable to this phenomenon, rather than to a simple dishonest behavior of single actors. It becomes clear that in such situation, the normalization concept needs to be redefined in the first place and, consequently, bring to new regulations system. Naturally, it is not about a simple repression of managers misbehavior but a complete rethinking of a "normality" concept.

In such context radical structures and processes reform are required in order to develop sense of social responsibility, necessarily favored and encouraged by a legal framework. In other words, it would be plausible to integrate the theory with practice through firm's statutes imposing a certain sense of responsibility from economic, social and environmental point of view. What's more, firm's internal measures should be integrated with external and global ones, in virtue of contemporary capitalism creation. 


\section{Between Scylla and Charybdis}

Both concepts analyzed previously, even if opposed, seem to place Italian companies (as also their leadership) in front of a hardly resolvable dilemma. In fact, both of them claim their models superiority and, as a result, require appropriate tools. Such dichotomy generates a sort of alternative between Scylla and Charybdis": with a perspective of crashing into a "rocky" vision of the firm structured in a "must-be" logic or with a perspective of drowning into the sea of contrasting interests to reconcile.

The fallowing situation may recall somewhat of déjà vu as far as it reminds past experiences, mostly revealed a failure, just like privatization process in the 90's. In fact, despite being favored by a common economic culture, these processes have generated only a shift from public to private monopolies or inefficient government control with a remarkable gap between costs and benefits.

It's useless, however, to claim an univocal concept of the firm. In fact, otherwise too much relevance would be given to rules and formal assets and less to firm's nature, in particular, to its ability to attract innovation processes autonomously. Consequently, the innovation- or to be more precise- its economic and social aspect is retained firm's structural factor.

In a contemporary context, marked by a diversity, pluralism and variety in terms of values and preferences, a unique firm's concept has no reason for being. Moreover, such consideration disagree with some authors claiming the supremacy of long-term assumptions and human resources valorization, which despite being success factors undervalue real subjects, their culture and preferences. Naturally, short-term and long-term perspectives coexist and will continue to coexist, just like preferences referable to value added generation or objectives of human resources valorization (personnel, professional competences).

Despite remarkable efforts in identifying a sort of "one best way", a researcher recognizes a variety of possible solutions and different variables configurations depending on objectives to pursue. Necessary to say, some of these variables, if applied correctly, may generate financial advantages, the result, however, is hardly predictable.

\section{Plurality and variety of institutional assets}

In front of an excessive strictness of some statements pronounced by economists, jurists and sociologists, it would be plausible to perform an analysis designed by Italian researchers through an institutional asset concept. To be more precise, the idea lies in expanding conceptual boundaries sketched out by the governance notion and, consequently, in recognizing different alternative models. According to this logic, the firm is an expression of structured relational system composed by subjects which confer essential contributions to its operator and, in reply, receive payoffs (Airoldi; 1998).

As certified, a corporate governance notion is outlined by considerations about institutional instruments, in particular about the functional aspect of management and control (just think about a role of management, board of directors, trade union disputes and company meetings). The institutional asset notion, on the other hand, 
covers a number of mechanisms designed to govern relations of influence and control in reference to single subjects and to corresponding contributions and payoffs. From this perspective, not only the firm's property structure is contemplated, but also the role of employers, credit institutions, clients, suppliers, possible network partners, public entities and community in general.

As a result, there is no space for "Scylla" or "Charybdis model" as far as other significant and often more efficient firm's assets have emerged. For instance, some medium-sized family businesses (assigning to family members a key-actor role in the company) raised during so-called "fourth capitalism" have managed not only to internationalize, but to be successful in dominating niche markets by a correct resources exploitation and close, confidential relations with banks, entrepreneurial relationships and local entities.

On the other hand, applying a "company-community" scheme to firm's assets model can be as well successful. Thus, it's about a convivial-type of company with no ambitions referable to stock market or to research \& development activities. Moreover, it is a small-sized company where innovation process is not referable to technological aspects but to "tailor made" orientation. As many examples show, a customer-driven innovation logic may constitute a relevant and inimitable success factor in global markets (Stefani, Trupia; 2003)

Some of fashion businesses, yet related to the founder's figure, have failed in modernization process after having involved managers deriving from non-fashion industries. Despite niche positioning, strong product and family ownership orientation, typically professional figure-centered, many Italian fashion houses have underestimated the role of marketing and cost control, operating at the expense of corporate competitiveness.

Reasoning on institutional assets, prompts to express preferences towards, for instance, dynamic solutions, strictly oriented to develop different subjects contributions, to balance the payoffs, to ennoble human resources as also to generate progress in civil systems (O'Reilly, Pfeffer; 2000; Airoldi, 1998). In particular, the companies retained as "socially capable" boast about attracting and keeping skillful professional figures as a result of a subject-centered orientation (Butera, 1999).

It is necessary, however, to keep in mind the variety of business typologies, often completely different, particularly in terms of institutional assets and organizational system quality.

On the other hand, it is still possible to come across different models, surely less brilliant and less gratifying, but still determining for numerous companies, all the more if dominated by an owner. In fact, the following situation persists first of all in contexts where social responsibility is missing and excessive personnel turnover is accepted.

The objective of this paper is clear: to underline the relevance of possible models variety rather than claiming ethical or effective superiority of one over another. Consequently, it's necessary to understand that society and fluid, complex economies request a wide range of alternatives, that is- possibility for all the subjects involved (not only top managers, shareholders but also personnel, clients, suppliers and financial institutions) to benefit from different choices. It's true, however, that the following statement has never been particularly treated by Italian management literature, even if Zappa and Masini are notable exceptions. Although 
their intellectual heritage is believed to be heavy, boring and supposedly outdated, paradoxically it has never been so valid and relevant as it is in the globalization era.

Surely, all the assets have their pro and con, strengths and weaknesses, and they are totally perfectible. It is incorrect, however, to consider them as artificial, control-oriented models with ambition to prove their functional superiority once applied in concrete, anomalous situations. Moreover, supposing the correctness of the following statement, any kind of spontaneous decision would be discouraged and the company itself would lack a necessary vitality.

\section{Firm's uniqueness in global capitalism context: the real challenge for managers and leadership}

It is still possible to come across a deceptive and illusory idea of globalization, frequently considered as a factor which dulls the differences between countries, institutions, companies and leads to uniform, flattened solutions negligently assumed with models retained successful in the international competition context. On the other hand, however, many companies proved how limiting the corporate models clustering can be. In fact, a winning entrepreneurial formula consists in its unique character even if best practices formulation, especially in very competitive industries, tends to equalize competitive behaviors. The companies believed to be best performers are particularly focused on developing their models in their own original and unique manner. The managerial process then, is treated like if it was a product, in other words, it's about building a some kind of a firm's processes label. Once again the entrepreneurship is a crucial factor, especially in a global competitiveness context. Thus, the companies are not likely to share their strategic, organizational and managerial models, quite the opposite, they commit to produce something unique and inimitable which constitute a winning model's framework.

Being unique and, consequently, kindle emotions and generate positive energy that involve personnel, clients, suppliers has surely a leadership connotation. Naturally, it is possible to find this kind of companies not only in the European context, but also in U.S and Asian emerging markets. At the same time, we assist an evident national firm's models erosion (models integrated and deeply rooted in corresponding political and institutional structures). Even if German, Japanese or French models still persist, the best performers operating in these countries decided to detach from national schemes and "row" towards firm's uniqueness.

Thus, it is necessary for managers to consider cultural, industrial, social and markets diversity, abandoning any kind of uniformity or standardization claim. However, there is still much confusion on this field, echoed in business literature and business schools disputes. Ghosal and Mintzberg, for instance, expressed particularly the negative impact of some managerial cultures not only on the society, but also on the company itself (just think about Enron scandal).

Nowadays, it is impossible not to consider contextual interdependence, similarities and dissimilarities coexistence. The managers have to reflect and listen, otherwise it is impossible to take advantage from diversity nor to increase the value of uniqueness. Only those who are capable to consider different backgrounds, succeed in understanding immediately their own context. 


\section{Resources and limits of the Italian case}

It would be plausible to apply some indications to the Italian case. First of all, it's necessary to identify one potentiality resource and one major limit.

The Italian companies and leadership uniqueness constitutes an enormous potentiality. In fact, many of fashion houses (like Diesel or Zegna) have managed to "brand" their firm's models making them unique and original. Their logic, necessary to say, is not management-centered but entrepreneurship-centered with a significant founder's personality footprint. Paradoxically, exactly because of their uniqueness, these companies have been living for decades in a sense of poor adequacy respect to prevailing benchmarks (Stefani, Trupia; 2003). Moreover, many subjects have never believed enough in their uniqueness and, as a consequence, they have never put a stress on quality concept promotion. Thereby, leaders have never become a reference point for the entrepreneurial community.

In global markets, however, where the uniqueness is greeted, a stress is put on creativity and entrepreneurial skills (just think about Made in Italy concept), both factors possibly developed by Italian companies. On the other hand, once historical heritage is considered, it is perceptible a negative, limiting and oppressive role of the State and of its principal institutions. According to Ida Magli it is possible to talk about a real treason committed by Italian leaders, emperors, dictators, politicians and popes on the Italian nation and on its rights in name of personal, purely egoistic interests.

The power's "palette" assumes different shades of craftiness, trickery, fiction, hypocrisy, and deception- personality structural elements of Italian political leaders. Such kind of slyness has become an emblematic behavior persisting in years and with no chance to fade, all the more in the actual political system.

The power concept has always been a favorite subject of Italian thinkers like Dante, Machiavelli, Guicciardini, Alfieri, Leopardi, Mosca whose originality and ideological independence distinguish perfectly Italian intellectual heritage. Moreover, their analytical and critical point of view (with a remarkable "historical footprint") have traced a kind of power guideline.

Even during the Maritime Republics and city-states period the economic force had to coexist with political structure weakness. In fact, economical vitality has always been mined by personal interests and inability to mediate conflicts between parties. Thus, an evident dichotomy between both, political and ideological point of view, erupts exactly in this historical period and persists till today in the form of managerial inefficiency (Salvati, 2003)

The great resource and huge limit, however, can be linked one to another. A union between diverse variables like geniality, entrepreneurial and innovative spirit, creativity (largely recognized to Italians especially in artistic field) and, on the other hand, the political system hostility seems to be evident. In other words, Italian entrepreneurs rebel against any kind of subjection through their greatest weapon- the creativity. Despite difficulties imposed by the context and a feeling of "loneliness", many brands have been actually successful in solidifying their competitive position. 


\section{Public Governance implications}

The following considerations may be applied in public governance. As emphasized previously, the firm has to avoid a trap of normalizing or regulating, metaphorically named as "Scylla and Charybdis" alternative.

The firm role as an operative and strategic subject of social and economic progress but also as a private institution pursuing public interest, requests however an adequate interpretation. Thus, it is impossible to limit to mere schemes of the economy - a science anchored in a past events analysis. Even the new managerial science risks to be subject to an illusory scientific interpretation, unmoral and simplifying schemes extended uncritically on complex social systems.

In the present context, European companies seem to suffer a sense of weariness, an impairment of vital energies expressed by growth rates, start-up failures, financial perspective predominance over the productive one, improper and opportunistic behaviors.

In front of the following situation, different economic, philosophical, scientific and legal cultures tend to pose approaches already seen in the past. The economists, for instance, profile intelligent forms of incentives and new corporate behaviors models by virtue of firms revitalization and progress. The philosophers are oriented to solve ethical problems through different instruments and rules in reference to social responsibility concept: code of ethics, social certificates and other similar measures oriented on correct practices diffusion. The scientists, promote the research, resources allocation and human resources training, while jurists propose reforms of systems conditioning the companies in terms of taxes and penal responsibility.

All of the following approaches are valid and detect real, concrete needs. On the other hand, however, they propose concepts already tested and, in some cases, obsolete. The incentive concept has acquired a purely economic dimension, very reductive if we consider the complexity of our economy. The code of ethic and other similar measures risk to reproduce viscous forms of bureaucracy. A stress put on research and knowledge reveals an excessive, almost enlightenment confidence in intellect. Finally, new rules can stiffen the legal system instead of generating new energies.

It becomes clear, that the following aspects represent half-truths and, consequently, can degenerate into classical "good intentions": obviousness hardly contradictable, but excessively rhetorical. Moreover, in some cases they can constitute a partial remedy and generate different effects respect to the planned ones.

While the normalization risks to "flatten" our companies according to extraneous models and to sacrifice our high uniqueness potential, the regulation blocks the entrepreneurship upstream. In fact, many companies have to struggle with increasing bureaucracy in reference to all its activities. Formalized control systems, on the other hand, are barely focused on an operative effectiveness improvement (Meyer-Rowan, 1991; Power, 1997) and various control forms are often rationalized into "ritual" inspections. It is not about a reassuring inspections, but about an effective progress expressed in quality and balance sheet certifications, and, in the nearest future, in CSR practices. 
The objective of this paper is to emphasize the importance of energies liberation, giving space to forces that already exist. There are far too many bonds, rules, conditionings imposed on the companies by European socio-political context. We operate in a jungle of regulations that strive to rule every aspect of our lives at the expense of public interest and in contrast with a principle of cost reduction.

The public governance is called to respond to social needs, all the more to the firms ones. As recent GLOBE's survey (carried out on middle managers from 62 countries) shows, Italian managers aspire to more future-oriented and performanceoriented society and less power-oriented. The leaders profile, on the other hand, seems to be in tune with cultural values: they are expected to help the society to move towards the better world and to help their colleagues to realize their personal ambitions.

Afterwards, a middle manager claims the necessity of value culture revitalization. According to this logic, personal interest is acceptable only if linked to the corporate one.

The question is: why the number of large and middle-sized Italian companies is so low? The answer is reportable to normative systems and regulating subjects operating in the tax, labor, security, environment and privacy field. Moreover, a state of infrastructure, energy costs and factory settlement conditions are also retained causes of such situation.

It would be possible to contrast the companies decline only in presence of new leadership model which not only inspires confidence, but also poses in contrast to economical and legal aspects objectivity. Thus, a real public governance duty is to promote managerial class renewal towards the system liberalization, norms simplification, giving to diverse social subjects a sense of responsibility and, in general, towards future-oriented behaviors.

This leadership model requests a structural plurality and variety, no longer considered as a limit but as a great opportunity. This cultural condition permits to respond perfectly to a significant value, needs and interest diversity that portrays all the society components and, by reflex, determines relations between demand and supply. Moreover, there is big variety of possible management and leadership stiles and none of them can be classified as the most efficient if we consider the uniqueness factor. In fact, it's managers task to "brand" the firms processes in virtue of value diversity emphasis. In the light of this logic, it becomes clear that the managers training contribute to cultural evolution and plurality only if not subject to a continuous models cloning. Thus, it's more about developing interpretation and listening skills applied consequently in multidimensional corporate reality. The sense of having a plurality of leadership models is even more complex and profound, as far as it lies in passing from the power logic to the powers development logic (Hillman, 2002). It involves a variety of power concepts, no longer based on subordination, but on reputation, persuasion and enthusiasm. 


\section{Notes}

${ }^{1}$ The myth has two sea-monsters: Charybdis lying on one side of a narrow channel of water and Scylla lying on the other side of the strait. Both sides of the strait are within an arrow's range of each other, so imminent that sailors striving to avoid Charybdis pass too close to Scylla and vice versa. 